\title{
Multilayered Ethics in Research Involving Unaccompanied Refugee Minors
}

\author{
MARIANNE VERVLIET
}

Department of Social Welfare Studies, Ghent University, Gent, Belgium Marianne.Vervliet@Ugent.be

CÉCILEROUSSEAU

Division of Social and Transcultural Psychiatry, McGill University, Canada

ERIC BROEKAERT

Department of Orthopedagogics, Ghent University, Gent, Belgium

I LSE DERLUYN

Department of Social Welfare Studies, Ghent University, Gent, Belgium

MS received August 2013; revised MS received November 2014

\begin{abstract}
Research articles about unaccompanied refugee minors (UM) have rarely addressed ethical issues. This is remarkable, given UM's specific, marginalized and vulnerable position within society, and the growing interest and developments in research ethics in refugee research. This article poses the question whether studies involving UM raise specific ethical issues compared to research on other refugee groups. We formulate personal reflections on ethical issues in a particular research project - a longitudinal study of UM in Belgium - and connect them to the existing body of literature on research ethics in qualitative and refugee research. We conclude that research ethics in studies with UM need to be multilayered because of researchers' obligation to take ethical responsibility at both the micro and socio-political levels.
\end{abstract}

Keywords: Informed consent, refugees, research ethics, unaccompanied refugee minors

\section{Introduction}

Children and adolescents below the age of 18 constitute about half of the worldwide refugee population and a large group among them are unaccompanied, being separated from their parents or legal guardian (UNHCR 2013, 2014). In 2013, 25,300 new asylum claims were lodged by unaccompanied refugee minors (UM) in 77 countries worldwide, which is the highest level since 2006, constituting about 4 per cent of the total number of asylum claims in those countries (UNHCR 2014). In 2013, Europe received more than half $(15,700)$ of UM's asylum claims, the greatest numbers being registered in 
Sweden, Germany, the United Kingdom and Norway (UNHCR 2014). Belgium received 1,771 UM in 2013, with as main countries of origin Morocco, Afghanistan, Guinea and Congo (Guardianship Service 2014: 'Statistics Unaccompanied Minors', unpublished).

Different human rights instruments, including and arising from the International Convention on the Rights of the Child, state that unaccompanied refugee minors are in need of special protection, implying that all UM must be granted temporary residence status and adequate care and reception (EMN 2010; FRA 2010). This population is considered 'vulnerable' because of their young age, combined with their status as refugees and their being unaccompanied by parents (Derluyn and Broekaert, 2008a; Derluyn and Vervliet, 2012). Accordingly, research on UM has often focused on UM's mental health, often demonstrating high incidences of a variety of mental health problems (see, e.g. Derluyn et al. 2008b; Derluyn et al. 2009; Bronstein et al. 2012; Fazel et al. 2012). Recent studies, however, have increasingly stressed the remarkable psychological strength, resilience and agency of UM, despite their high risk of facing traumatic experiences and daily stressors and of developing psychological problems (see, e.g. Luster et al. 2010; Ni Raghallaigh and Gilligan 2010). In our longitudinal research project, about which we report in this article, we therefore consider UM through an integrative, holistic lens: as dynamic human agents who are part of dynamic systemic contexts (on micro, meso and macro levels) and who at the same time exhibit both vulnerabilities and abilities and capacities (Vervliet et al. 2013a).

It has been widely stressed that working with UM requires high professional, ethical standards, as needed for all children and adolescents in specific situations of child protection (Derluyn and Broekaert, 2008a; FRA 2010; Vervliet et al., 2013a; Vervliet et al. 2013b). It is therefore self-evident that we use comparable standards when doing research with this population (ERIC 2014). It remains unclear, however, which specific elements of this ethical responsibility arise when doing research involving unaccompanied refugee minors. This question occupied a central place in our longitudinal mixed-methods study of UM in Belgium. Throughout the follow-up of a group of UM $(N=103)$ during the first 18 months of their residence in Belgium, we were confronted with numerous challenges that we experienced as 'ethically important' and that were primarily situated in the researcher-participant relationship, in the bonds created, and in the emotions and questions this evoked on both sides. Confronted with these ethical challenges in the research project, we noticed that, while ethics in research on refugee groups is increasingly receiving the attention of researchers (see, e.g. Leaning 2001; Jacobsen and Landau 2003; MacKenzie et al. 2007; De Haene et al. 2010; Zion et al. 2010), few studies have addressed ethics in research specifically with UM (Thomas and Byford 2003; Hopkins 2008). Moreover, although very valuable, these studies mainly focused on methodological and procedural ethical issues (e.g. ethical approval, informed consent, privacy, confidentiality and dissemination), which only partially covered the ethical questions we encountered during our research project. 
This article therefore aims to further investigate points of particular interest concerning ethics in research involving UM, through sharing and analysing 'thick descriptions' (Brinkmann and Kvale 2005) of personal reflections on ethical challenges and related research actions in our longitudinal, mixed-methods study with UM. Going beyond 'procedural ethics' (Guillemin and Gillam 2004), we will reflect on 'relational ethics' (Ellis 2007), in doing so referring to the work of Levinas (1906-95). The core of Levinas's thinking is the interpersonal, asymmetrical relationship between the 'I' and the 'Other' - a relationship wherein the 'I' receives an inescapable moral appeal to take up his/her unique responsibility for the 'Other', and for all 'Others' (Duyndam and Poorthuis 2003; Egéa-Kuehne 2008). Levinas's 'philosophy of the Other' gave us important support in gaining a deeper understanding of our emotions and actions in the research process, as it challenged us to rethink and reframe our own initial reflections (De Schauwer and Van Hove 2011).

We will first introduce the aims and methods of our study and its participants. Second, we will introduce vignettes that illustrate the follow-up in the cases of three Afghan participants, Nabi, Hamid and Hazratullah (pseudonyms), using extracts from the researcher's ([Marianne Vervliet], first author) personal notes. Third, building on these vignettes as reference points, we will share reflections on six central themes that were ethically highly important throughout our research journey. Finally, we will argue that researchers' ethical responsibility in studies of UM concerns both being an 'ethical researcher' and doing 'ethical research' (Vandekinderen et al. 2013) and is thus situated on a micro as well as on a macro/socio-political level.

\section{Study Aims, Methods and Participants}

The central aim of our research was to gain more insight into possible evolutions in the mental health, aspirations, feelings of agency and lived experiences of a group of UM during their first 18 months in Belgium. We also wanted to support practitioners (social workers and legal guardians) and policy makers by making this enlarged knowledge available.

The study took place between 2009 and 2012, and started during the participants' first weeks in Belgium, in the two reception centres where all newly arrived UM are cared for (see below for an extensive description of the first moments of contact). During the following 18 months, all participants $(N=103)$ were met at least twice (at six and 18 months). At each encounter, a semi-structured interview was conducted and the participants were asked to complete several self-report questionnaires. Central topics in both the questionnaires and the interview were participants' aspirations, mental health, traumatic experiences, daily living experiences (positive aspects and stressors) and feelings of agency. In between the face-to-face meetings, regular telephone conversations with all participants took place to keep track of them. In the context of a case study focusing on Afghan UM, 13 of the Afghan 


\section{Marianne Vervliet et al.}

participants were also encountered at least five additional times, each including a semi-structured interview related to the same themes.

Most participants were male (84.5 per cent), the mean self-reported age at arrival was 15.99 years $(\mathrm{SD}=0.85$, range $14-17)$ and the most frequent countries of origin were Afghanistan (46.6 percent), Guinea (19.4 percent) and Congo (5.6 percent). Twenty-four participants did not participate at the second measurement moment (after six months' stay in Belgium), of whom 13 participated again at the third measurement moment (at 18 months). Fifteen adolescents dropped out between the second and third measurement moments. Drop-out reasons at the second and third measurement moments were that participation was emotionally too demanding (20), participants had disappeared or could not be reached anymore (10), they had left the country (3) or they lacked time to participate (6).

The research team consisted of the researcher ([Marianne Vervliet], first author), who followed all Afghan participants; research assistants, each of whom followed about 10 participants from other countries of origin for 8-12 months (two research assistants successively followed one participant); and interpreters for the different language groups. This research team collaborated intensively: the research assistants were supervised by the researcher in monthly group meetings and individual in-between contacts; and the researcher was individually supervised at least every two weeks by [Ilse Derluyn] (co-author) as an 'ethical auditor' (Hugman et al. 2011a) and on an annual basis in meetings with academic and practitioner guidance committees.

Before the sampling started, ethical approval for the study was obtained from the Ethical Committee of the Faculty of Psychology and Educational Sciences of Ghent University.

\section{Following Nabi, Hamid and Hazratullah: Three Vignettes as Reference Points}

\section{$\mathrm{Nabi}$}

18 August 2010: First Encounter This is Nabi's second day in the (first reception) centre. He says he has not yet had an opportunity to talk with his social worker and that he does not feel at ease with the other residents. He opens up about the many hazards he encountered along the way to Europe, such as being swept overboard when crossing from Turkey to Greece and believing he was going to die because he could not swim. I am deeply touched by his story and realize that the interpreter and I are possibly the first persons with whom he has shared these experiences and feelings since his arrival. This impresses me greatly.

1 October 2011: Seventh Meeting (Nabi is now over 18 years old (according to an age test) and has transferred from the residential centre for UM, where he lived for almost a year, to a small local residence for asylum seekers. He no longer has a guardian.) Nabi says he has received subsidiary protection 
status. This allows him to stay in Belgium for at least one year, with possible renewal thereafter. Nabi says: 'When I got my decision, one month ago, all my stress was gone, but now I have to run after my other problems.' As the regulations stipulate, with this particular decision, he has only two months to find his own private housing and leave the refugee residential centre, but so far he has not been able to find a flat he can afford.

3 October 2011: Phone Call Nabi asks if I can help him to search for accommodation. First, I ask what he has done already to find a house and how he wants me to help him. He explains that he has been searching and asks if I can help him to search in the city, where he knows I am living. I search in some estate agents' online databases and send him an e-mail with some advertisements for flats to rent.

9 December 2011: Text and Phone Call Nabi sends me a text: 'Hello [Marianne], I would like to talk with you.' When I call him, he says: 'I really have so many problems, I've still no house and no work.' We make an appointment for tomorrow.

10 December 2011: Eighth Meeting I am shocked when I see Nabi. I get the impression that his health has broken down completely during recent months, both emotionally and physically. He looks tired, has lost weight and seems to feel miserable. He says that he has not managed to find a house yet, that he had to leave the residence one month ago, and that he has been moving continually between friends living in different cities and willing to give him shelter, he himself being without any money. He says he feels exhausted, sad and guilty towards his friends. He asks me: 'Can you show me the way? What do I have to do?' and says: 'If you receive documents you have to do everything on your own, they don't help you anymore.' At first, I don't really follow up the question as to what I could do, but ask him if he wants to tell me how he feels and what has happened since our last meeting: what actions he has taken and what other people, such as his social worker, have done to find a solution. He says that the social worker did not help him and seems not to care about him and that he feels lost since all his own actions to find a flat are failing. Then he asks again if I can help him. First, I try to support him emotionally by saying that I understand he is in a very difficult situation and also that I believe he has already taken some very good actions in his search for a house. Then, I try to make it clear that I don't have any magical solution, but that I want to think together with him about what he could do. I ask if he could contact his former social worker to ask for her help again. But he says he does not trust her anymore. Because I am not familiar with residence policies for people with his particular documents, I ask if I could contact her to obtain more information about who is legally authorized to support him right now. I also tell him I could contact organizations 
supporting young refugees to ask what they could do. He agrees with these proposals and I also try to encourage him to keep on searching.

12 December 2011: Phone Call I call Nabi's former social worker to inform her about his precarious situation and ask what he could do. I get the impression that she feels accused by my questions, certainly when she tells about all actions she has taken already in order to help him. And it sounds as though she believes I am following Nabi too much in what he says.

13 December 2011: Phone Call I call Nabi to give information about the rules and jurisdictions and advice from the organizations I have contacted. He clearly appreciates this a lot.

\section{Hamid}

8 November 2011: Fourth Meeting Hamid tells me that he is tired of the life in the asylum centre, where he has already lived for more than one year, especially because there is no progress in his asylum procedure. He complains about his guardian: the man visited him only a few times, does not call, and gives the impression of not being concerned. For example, when two months ago he was very ill and even hospitalized for several weeks, his guardian did not show up, which he thinks is a real shame. I ask him if he has raised his complaints with his social worker. He says he has not done this yet and I again encourage him to do so. But he says he does not believe that the social worker can really help him with this.

11 November 2011 I have now met in total four participants with the same guardian as Hamid, who shared similar complaints. The more I hear them complain, the more I feel in strong disagreement, and even angry, with how this guardian is treating them and (not) taking up his responsibilities. I also realize that I probably have more information about this guardian than the participants' social workers. I have a growing and intense feeling that 'I have to do something, I cannot leave it like that'. I decide to follow the same strategy with Hamid and the other participants: I talk both with them and with their social workers, and explicitly pass the message to all the participants that they have the legal right to make an official complaint against their guardian and ask for another guardian to be appointed. I also tell them that I am prepared to support them in this process and to look for the best way to do this, together with their social workers. I also consider making a complaint against this guardian myself, but we (my supervisor and I) decide that it seems better not to do this, since ethically, I would need the consent of all the participants and social workers concerned. We also think it would be better to support the participants in making their own complaint if they want, because this is an action they can take themselves and which could strengthen their self-respect. I also realize that this is probably much more the action 
field of social workers. Positioning myself (as a researcher) between several actors might make it confusing for the young people involved and I run the risk of creating a negative image of social workers' support if I go too far in an action like this.

\section{Hazratullah}

5 November 2010: E-Mail from Staff of the First Reception Centre Based on his age assessment test, the migration authorities have decided that Hazratullah is over 18 years old.

13 January 2011: Text and Phone Call He sends me a message: '[Marianne] please call me.' When I call, together with the interpreter, he says he is being detained in a closed centre and we understand this is because of the Dublin regulations, as he has already applied for asylum in Switzerland. He asks if we can call his lawyer to ask for his support. We phone the lawyer and pass his answer back to Hazratullah: if he faxes the documents he received at his imprisonment, the lawyer will consider what he can do to help.

26 January 2011: Fourth Meeting-Second Visit in Detention Centre, One Week before His Deportation He is having an extremely difficult time in the centre. He says he is very grateful for our visits and phone calls. When we go he says: 'I will not abandon you.'

29 August 2011: Letter I receive a letter and a drawing from Hazratullah in Switzerland. He writes:

Hello [name of interpreter], I wish you a lucky Eid [end of Ramadan]. Thank you [Marianne]. I wish you all the best. Please stay in contact. Best of luck my friends.

28 December 2011: Phone Call Hazratullah calls me: 'I just want to say that I'm free! I just heard that I can leave today. I'm so surprised. I will call you later.' He sounds very happy that he can finally leave the closed detention centre where he has been living for almost one year now.

10 March 2012 Several missed calls from Hazratullah. I call him back and ask how he is doing. He is tired of living in the asylum centre in Switzerland, where he is waiting for an answer in his asylum procedure, and says that he is planning to go to the United Kingdom. He feels that he cannot wait any longer because he has to earn money to support his family. He asks if we [the interpreter and/or I] can lend him money to make the journey. He knows somebody who can arrange the trip for him, and he will certainly pay us back. I tell him that we cannot do this, because we are following many other young people and that we cannot possibly give money to everyone. 


\section{Marianne Vervliet et al.}

He repeats his question and, when I respond similarly, he says: 'It's okay', but he sounds disappointed. I propose making contact with the local non-governmental organization (NGO) that supported him before (on an emotional and juridical level), but he answers: 'Everybody says I need to wait, but they make me crazy by saying that, I just cannot do that!' I feel guilty, very uncomfortable and worried, but I feel that giving money may also create unrealistic expectations of me and be unfair towards other participants.

\section{From 'Stepping In' to 'Stepping Out': Six Ethically Important Themes throughout Our Research Journey}

\section{Stepping In: First Contact with Participants}

Our first encounter with the participants took place in one of the two reception centres for newly arrived UM. The centres' psychologists, as 'gatekeepers' (Hopkins 2008), introduced the study to all newcomers over 14 years old (we considered participation too demanding for younger UM) and, if they were interested in taking part, a meeting was organized between participant, researcher and an interpreter. In this meeting, we first gave a description of the research aims and conditions, to enable participants as far as possible to make their own decision about whether to participate and on what terms (Guillemin and Gillam 2004): the freedom not to participate, to stop participation at any moment or not to answer questions; the confidentiality of all information; and the independence of the study from the migration authorities and their decisions (both positive and negative). We stressed that participation would not imply any positive impact on their residence procedure, and that non-participation would not impact their procedure negatively. We also explained why we wanted to ask to audiotape the conversations (and the freedom to refuse this) and we gave the researcher's contact information, stating that they could always contact us with additional questions about the research or to receive emotional support. Concerning the latter, we had already made agreements with several psychologists before starting the study to refer participants, if needed. After the participant gave his oral consent, a written informed consent was explained and signed. Although we felt that it was not easy for the participants to understand what was happening (who were we, why did we come to meet them, what is research, etc.?), we tried to explain these different aspects the best we could, and we also tried to avoid creating unrealistic or erroneous expectations of us or the research (Leaning 2001). In this regard, it was necessary to take time (usually about one hour) for extensive and repeated explanations and, through the twofold informed consent (oral and written), we tried to enhance participants' understanding of the project and the freedom of their participation, as a first step in a continuous, iterative informed consent process (MacKenzie et al. 2007; De Haene et al. 2010; Hugman et al. 2011a, 2011b). After the first phase of information and consent, the first 
measurement took place. Often, when the phase lasted long or was intensive, the measurement was partly or entirely moved forward to a separate meeting, usually a few days later. Further, their legal guardian was also informed about their participation and was also asked to sign an informed consent.

All measurement moments were followed by a debriefing (Thomas and Byford 2003; Block et al. 2013): we asked how participants felt about the study and whether they wanted to continue. This enabled both positive (feeling relieved to talk about their experiences, being happy to contribute to research, etc.) and negative aspects (seeing no direct personal advantage in participation, perceiving the questions as emotionally too demanding, etc.) to be mentioned (Newman and Kaloupek 2004; De Haene et al. 2010). While, for most participants, the positive aspects seemed to prevail, some decided to cease participation, usually after the first or second meeting.

\section{On the Way: Creating Mutual Bonds}

A longitudinal follow-up of the participants meant that we had regular contact with them. This process spontaneously created a particular bond between participant and researcher.

For the participants, certainly at the start of the research, what we did seemed remarkable: we wanted to keep contact and come back to them time after time, regardless of where they lived, the result of their age assessment test, their legal status or whatever else had happened or changed in their lives since the previous meeting. At the same time, we noticed that the aim and conditions of our encounters and the study had to be repeatedly explained, leading to a renewal of the oral informed consent (De Haene et al. 2010; Hugman et al. 2011a, 2011b). Both aspects, the continuous character of the relationship and the iteration of consent, were in our view crucial for a growing trustful relationship between researcher and participant (Hynes 2003; MacKenzie et al. 2007). The role of the interpreters also turned out to be highly important in creating relationships of trust (Thomas and Byford 2003; Björn 2005; Rousseau et al. 2011).

However, as illustrated by the vignettes, this level of trust, and the meaning and importance the participants attached to their contacts with us, differed markedly between individuals and changed over time. While Nabi, for example, talked openly from the first meeting onwards, Hamid was much more reserved at the beginning, so that we thought he would not agree to further participation, but he gradually became more willing to talk and towards the end of the study he himself invited the researcher to come.

Not only did the participants' attachment to us grow; we also experienced connectedness with the participants and became deeply affected when they opened up to us, such as about their often extremely difficult life experiences. Such emotional upheaval, when confronted with this sort of story, is quite common for all professionals working with refugee groups and sympathy for the plight of people is even considered as necessary to meet professional 
standards (Barsky 2000; Guzder and Rousseau 2013). As illustrated by the vignettes, this sympathy often strengthened during the follow-up, when we were constant and close witnesses of the many challenges, constraints and predicaments in participants' daily lives: we experienced strong feelings of anger, indignation, injustice and powerlessness (because the problems seemed so big and insurmountable) and we were often worried about the participants' health and safety. According to Levinas, my sensibility, that I am 'touchable' by and for the Other, is the condition for my own being, my existence, a radical passive condition:

In spite of myself I find myself turned outwards - my interiority, my psyche, my soul, are turned outwards by 'being moved in spite of myself'. My being-self consists in standing turned outside of myself, without first turning myself, as an active subject, towards the outside. The 'I' is to be bare, exposed (Burggraeve 2006: 92).

Mutual bonds and connected empathy and emotions are natural components of human relationships, especially in long-term relationships (Hoffman 2000). The longitudinal method of this study therefore showed important advantages on an ethical level, as it helped to prevent doing harm to participants (ERIC 2014). As building trust in relationships with UM takes time, we cannot 'rush in' and we cannot simply 'rush out', as breaking boundaries of trust may be very harmful for young people who are already largely confronted with substantial losses (Kohli 2006). For us, this slow rhythm was an opportunity to respect the differing tempi of participants. At the same time, we were aware that these bonds were also fruitful for our research on a methodological level: since we wanted to investigate how their wellbeing evolved over time, the trust created led to continued participation and openness in the participants' responses. We also realized that these mutual bonds introduced important and numerous ethical challenges, which we will discuss below.

\section{Taking Action in a Complex Context: Acknowledging and Responding to Appeals}

We frequently received explicit requests for help from participants who found themselves in different difficult situations in Belgium, as illustrated by the vignettes about Nabi and Hazratullah. We perceived these requests as expressions of agency: participants consciously made the choice to appeal to the researcher, aiming at initiating change in their situation (Kuczinski 2003). At the same time, this also indicated how they perceived the researcher: as a potentially powerful member of society who could have a particular influence (Kohli 2006; Chase 2010).

In other situations, participants did not make explicit requests, but rather we, as researchers, felt the urge to help them. The latter often happened in cases where participants attributed the fact that they faced particular difficult 
living situations to the lack of initiative of people they were depending on, such as their social worker or guardian, as illustrated by the vignette about Hamid. According to Levinas, my sensibility for the Other makes me an ethical being, which means that I can be appealed to (Burggraeve 2006). In my relationship with the Other, I receive a moral appeal from the Other, which is a strong invitation to take responsibility for the Other or a primary obligation to care for the Other that I have to fulfil, meaning that I not only have to refrain from neglecting the Other myself, but must also do something (Duyndam and Poorthuis 2003).

The appeals arose in day-to-day research practice and we felt that our responses would have consequences on an ethical level; we could say that these appeals were 'ethically important moments' (Guillemin and Gillam 2004). As the appeals usually came suddenly and unpredictably, we could not anticipate, reflect on or consider the pros and cons of possible responses. In any case, not responding to these appeals (or not taking any concrete action) was simply not an option (MacKenzie et al. 2007; Düvell et al. 2010). In Levinasian terms, we could say:

The appeal of the Other is so strong that I cannot do other than follow and serve. It demands a response that cannot be prepared beforehand, I have to surrender.... I am no longer in control (De Schauwer and Van Hove 2011: 5).

We also felt that we, the researchers, and nobody else, had to respond directly to the participants' appeals: 'Responsibility is what is incumbent on me exclusively, and what, humanly, I cannot refuse' (Levinas 1985, in Biesta 2008: 205, emphasis in the original).

My primary responsibility for the Other is not something over which I have any choice, but I do have a certain freedom in fulfilling my responsibility: I have to consider for myself what I must do (Duyndam and Poorthuis 2003). However, this was not at all self-evident during the research: because of the unpredictability of the appeals, it was often not immediately clear what response was, ethically considered, 'preferable'. Step by step, however, we experienced that besides remaining in contact with participants' suffering (De Haene et al. 2010), giving information to a participant ourselves, seeking information from others (social workers, guardians or other organizations) and passing it to the participant, or referring a participant to others (psychologist, social worker, guardian, lawyer, etc.) could all be valuable supporting actions or responses to participants' appeals (Hopkins 2008; Düvell et al. 2010).

\section{The Boundaries of Researchers' Responsibility}

In this continuous process of searching for worthwhile responses, we struggled with the 'boundaries' of our responsibility for the participants in several ways. First, a major and overarching challenge was that our responses had to take place within a complex, continuously evolving context surrounding each 


\section{Marianne Vervliet et al.}

particular young person, involving a range of actors with differing roles (guardian, social worker, lawyer, friend, family, etc.). Creating partnerships with guardians and social workers was in itself a necessity in the research. However, these partnerships sometimes became complicated when facing participants' appeals and we had to move in areas of tension, taking into account other actors' roles and opinions, despite the fact that they sometimes contrasted with our own or the participants' opinions, as illustrated by the vignettes about Nabi (social worker) and Hamid (guardian). Although not always easy, consultation and dialogue with the other actors (Thomas and Byford 2003; De Schauwer and Van Hove 2011) clearly appeared to be ethically necessary for creating worthwhile responses to the participants' appeals, since the other actors in the UM's contexts were 'the thirds' in Levinasian terms, referring to the larger society (Duyndam and Poorthuis 2003): the participants, the researchers and the other actors were all 'Is' and all 'Others'. This means that we all had a responsibility towards each other, that the responsibility of the other actors for the participants limited our responsibility for them and that we had to try to adjust our actions to theirs. What made this balancing act especially difficult was our perception, elicited by the young people's narrative, that certain other actors seemed not able to fulfil their mandates in a way which responded to the young people's expressed needs (see the role of the guardian in the vignette about Hamid). Importantly, the other actors we refer to here are not only individuals, such as guardians or social workers, but also broader societal structures, such as education and care services. For example, we preferred to refer participants to external professional psychologists instead of taking this role ourselves, but were confronted with a lack of experience with UM in psychological care services (leading to a refusal of treatment) and long waiting lists.

Second, although the stories of the participants and their high level of need (as was confirmed by our research findings; see Vervliet et al., 2013a, 2013b; Vervliet et al. 2013c) could lead to a perception of the responses of other actors as inadequate, we found we had to refrain from adopting a 'saviour' position through taking action that would position us as only 'good' and would then introduce a split with other actors. We perceived it, for example, as 'unethical' to take actions such as giving money to participants, since we believed this could create expectations that we would never be able to sustain in the longer term and thus could do more (long-term) harm than the (shortterm) benefit gained (De Haene et al. 2010; ERIC 2014). Moreover, such actions were impossible to take for all participants, and we also had our responsibility towards the 'other Others' (Duyndam and Poorthuis 2003). Nevertheless, as illustrated in the vignette about Hazratullah, it was emotionally difficult to say 'no' to those appeals, leaving us with feelings of guilt and anxiety, since we became, like other adults, also unsupportive. Doing injustice to the Other thus seems inevitable when drawing lines around our areas of responsibility (Duyndam and Poorthuis 2003), so as to 'do no harm' in a 
researcher-participant relationship (De Haene et al. 2010), and we had to mourn the loss of an omnipotent position.

Third, another challenge in the balancing act of responding to appeals was to not overlook the agency of the participants themselves (MacKenzie et al. 2007; Rousseau and Kirmaeyer, 2010; De Haene et al. 2010). Taking over actions that participants could take themselves might create unattainable expectations of us, even dependency, and would probably also negatively impact their feelings of self-esteem. This would run utterly counter to our basic assumption that UM were dynamic human agents who could make sense of their environment, initiate change and make their own choices (Kuczinski 2003). We therefore tried as much as possible to empower participants to support and encourage them in taking initiatives themselves, encountering them as 'Is', able to be responsible for themselves and towards 'Others' (Duyndam and Poorthuis 2003). Although sounding strong in theory, in practice, the boundaries of this approach appeared thin and fragile. For example, it was often unclear whether it would be better-for the participants, in responding to their difficult situation - to contact social workers, lawyers or others ourselves and/or to stimulate the participants to do so. This resulted in an important continuous search for ways to support participants' agency in each specific situation.

\section{Channelling Researchers' Emotions}

Obviously, our strong feelings (anger, indignation, injustice, powerlessness, worry, etc.), which emerged because of the participants' experiences and were influenced by the bond we felt with them, challenged our position as researchers (Jacobsen and Landau 2003; Zwi et al. 2003; Düvell et al. 2010), although this is a natural process and it is considered necessary to be open to these feelings as professional (Barsky 2000; Guzder and Rousseau 2013). Channelling our emotions was thus pivotal, as it could help to avoid exceeding the boundaries of our responsibility. This channelling was made possible by, amongst other methods, keeping a research diary, self-reflection, and discussion with other researchers and supervisors (Morse 2007).

\section{Stepping Out? Finishing the Research}

Another boundary we encountered concerned finishing the research. In research relationships with UM, we cannot 'rush in', as building trust takes time, but we also cannot simply 'rush out', as breaking boundaries of trust may be very harmful for young people who are already confronted with substantial losses (Kohli 2006). Throughout the research process, we became more and more aware of the importance of being cautious about when to finish our follow-up. But, in this final phase, we also could not completely avoid 'doing harm' (De Haene et al. 2010) and therefore tried to minimize harm by taking time in the final visit to explain as clearly as possible what the next steps in the research would be (analysis, reporting) and 


\section{Marianne Vervliet et al.}

that we would not initiate a new meeting ourselves. At the same time, we made sure participants had our contact details and we emphasized that, if they wanted, they still could contact us in future. We also thanked them for their participation and commitment and, as a sign of appreciation, they received a gift card (worth $€ 15$ ) for a multimedia/clothes shop. This was not announced beforehand because we wanted to avoid its influencing research participation. Moreover, we continued to send text messages at (Afghan) New Year and other holidays, both out of respect and to show our contactability. Nevertheless, since we continued to experience appeals during this phase (e.g. some participants remained in contact and/or asked for our help), we sometimes had the feeling that to some extent we had abandoned the participants.

\section{Conclusion}

In this article, we have illustrated the many ethical challenges in the practice of our particular longitudinal follow-up study of UM: at the start of our relationship with the participants, in the development of mutual bonds, in responding to participants' appeals, in the boundaries of researchers' responsibility, in channelling researchers' emotions and in finishing the research. The ethical challenges changed the research as initially planned and expected: it became more intensive, intrusive and complex for the researchers, especially because of the 'extra' actions (and connected reflections) in response to participants' appeals.

The ethical issues, meaning our ethical responsibility for the participants, appeared to be coloured by the specific method we used, as well as by the specificity of UM as a refugee group. First, because of the longitudinal follow-up method, we were confronted with an ongoing ethical responsibility, from the first until the last moment of contact with the participants, which had ethical implications on 'procedural' and 'relational' levels. 'Procedural ethics' (Guillemin and Gillam 2004) for this method especially implied the necessity of an iterative or repeated informed consent process (MacKenzie et al. 2007; Hugman et al. 2011a, 2011b; ERIC 2014). Repeated explanations of aims and research conditions were necessary, since a good understanding of these elements needs time. A longitudinal design brings in the possibility of 'having time' and thus also of being able to adapt the informed consent process to each individual's tempo. 'Relational ethics' (Ellis 2007), referring to the recognition and value of mutual respect, dignity and connectedness between researcher and participant, appeared highly significant. The followup, with regular face-to-face contact moments, led to the development of long-term relationships: we stepped inevitably into the participants' context and became - temporarily and to a varying extent - part of their lives, thereby creating mutual bonds, marked by trust and empathy. Longitudinal research on UM thus clearly has strong added value on the ethical level (Kohli 2006). 'Relational ethics' also became complex, since within and because of the 
duration of the relationship and the mutual bonds, the various appeals, as 'ethically important moments' (Guillemin and Gillam 2004), emerged in day-to-day research practice, leading to a strong need to respond. Above all, the connectedness intensified the emotions we experienced when confronted with participants' problems.

Second, while the ethical issues discussed above relate to the method and thus might count for all refugee groups, their concrete expression in our study appeared to be significantly marked by the specific situation of UM. Both the fact that the participants were young and separated from their parents and our knowledge of their emotional vulnerability (Derluyn et al., 2008b; Derluyn et al. 2009), confirmed by the results of our study (Vervliet et al., $2013 \mathrm{a}, \mathrm{b}, \mathrm{c}$ ), intensified our feelings of responsibility for them. Moreover, the struggle with the boundaries of our responsibility for the participants was further complicated by the experience that 'the thirds' (in Levinasian terms) or other actors in the participants' context (social workers, guardians, psychological services, etc.), often seemed not able to take appropriate responsibility for them. This put us under pressure to take up (parts of) 'their' responsibility. We should stress here that the reasons why the other actors could not take up their responsibility, and why the participants often found themselves in a situation wherein they lacked adequate support, could - in general-be situated on the macro level, the level of migration policy, and not on the micro level, the level of the individual social worker-participant interaction. As we showed earlier (Derluyn and Broekaert, 2008; Vervliet et al., 2013a, b), migration policy fails lamentably to provide UM with adequate high-quality support, resulting in a situation wherein practitioners far too often find themselves in a deadlock between what they perceive as the needs of the participants and the limitations imposed by migration policy on the scope of the support they can provide (Derluyn and Broekaert, 2008; Vervliet et al., 2013a, b). As a consequence, we could say that the macro context of policies towards UM importantly influenced the struggles with our own ethical responsibility towards them on the micro level.

This finally implies that research ethics in studies of refugee groups (in general) are multilayered: it is not only our responsibility to be 'ethical researchers' (Vandekinderen et al. 2013) on the micro level in relation to the participants and their social and support network, but also to do 'ethical research' (Vandekinderen et al. 2013) on the macro/socio-political level. As researchers, we are able to identify shortcomings in the support that refugee groups receive, which implies that we are also responsible for denouncing these deficiencies on the level of policy and related practice, and that we should advocate for improvements on behalf of refugee groups (Rousseau and Kirmayer, 2010). Also on a macro level, our ethical responsibility is thus marked by the UM's young age, lack of parental support figures and emotional vulnerability, and the shortcomings in the educational and psychological care structures for them. 


\section{Marianne Vervliet et al.}

However, the concrete interpretation of our responsibility on the micro and socio-political levels is not fixed: we need to take decisions ourselves over and over again during each research project, which implies a process of continuous reflection (Hopkins 2008; ERIC 2014), negotiation and action, in each particular 'ethically important' situation: what are 'preferable' actions and for whom; and what are the boundaries to our ethical responsibilities? On the micro level, we should try to take all necessary actions in responding to appeals, as well as to place the necessary limits on our responses towards the participants and their social and support network to preserve their and our own wellbeing. In this, supporting UM and their networks' agency is a main point of reference. On the macro level, we should advocate for improvements on behalf of refugee groups, but consider the limitations of our advocacy by acknowledging our multiple (and often conflicting) loyalties: first, towards the subjects and the (refugee) communities they represent; second, towards the academy; and third, towards the society of which we form part and with which we are always (at least partially) complicit (Jacobsen and Landau 2003; Rousseau and Kirmaeyer, 2010).

\section{Acknowledgements}

We are indebted to all participants, their guardians and all the centre staff involved. Our thanks go to the research assistants and interpreters for their contributions. Thanks to Elisabeth De Schauwer for the introduction to the work of Levinas. The support of the European Refugee Fund and the Special Research Fund of Ghent University made this research possible.

BARSKY, R.F. (2000) Arguing and Justifying: Assessing the Convention Refugees' Choice of Moment, Motive and Host Country. Vol. 1. Burlington, USA: Ashgate, pp. 95-109.

BIESTA, G.J.J. (2008) 'Pedagogy with Empty Hands: Levinas, Education and the Question of Being Human'. In Egéa-Kuehne, D. (ed.) Levinas and Education: At the Intersection of Faith and Reason. New York, NY: Routledge, pp. 198-210.

BJÖRN, G.J. (2005) 'Ethics and Interpreting in Psychotherapy with Refugee Children and Families'. Nordic Journal of Psychiatry 59: 516-521.

BLOCK, K.D., WARR, L., GIBBS, L. and RIGGS, E. (2013) 'Addressing Ethical and Methodological Challenges in Research with Refugee-Background Young People: Reflections from the Field'. Journal of Refugee Studies 26(1): 69-87.

BRINKMANN, S. and KVALE, S. (2005) 'Confronting the ethics of qualitative research'. Journal of Constructivist Psychology 18(2): 157-181.

BRONSTEIN, I., MONTGOMERY, P. and DOBROWOLSKI, S. (2012) 'PTSD in AsylumSeeking Male Adolescents from Afghanistan'. Journal of Traumatic Stress 25: 551-557.

BURGGRAEVE, R. (2006) 'From the Self to the Other and Back to the Self-Otherwise: Levinas' Redefinition of the Subject'. Subject Matters 3(1): 75-104.

CHASE, E. (2010) 'Agency and Silence: Young People Seeking Asylum alone in the UK'. British Journal of Social Work 40(7): 2050-2068.

DE HAENE, L., GRIETENS, H. and VERSCHUEREN, K. (2010) 'Holding Harm: Narrative Methods in Mental Health Research on Refugee Trauma'. Qualitative Health Research 20(12): 1664-1676. 
DERLUYN, I. and BROEKAERT, E. (2008a) 'Unaccompanied Refugee Children and Adolescents: The Glaring Contrast between a Legal and a Psychological Perspective'. International Journal of Law and Psychiatry 31(4): 319-330.

DERLUYN, I., BROEKAERT, E. and SCHUYTEN, G. (2008b) 'Emotional and behavioural problems in migrant adolescents in Belgium'. European Child \& Adolescent Psychiatry 17(1): 54-62.

DERLUYN, I., MELS, C. and BROEKAERT, E. (2009) 'Mental Health Problems in Separated Refugee Adolescents'. Journal of Adolescent Health 44(3): 291-297.

DERLUYN, I. and VERVLIET, M. (2012) 'The wellbeing of unaccompanied refugee minors'. In Ingleby, D., Krasnik, A., Lorant, V. and Razum, O. (eds) Health inequalities and risk factors among migrants and ethnic minorities. Vol. 1. Antwerpen/Apeldoorn: Garant, pp. 95109.

DE SCHAUWER, E. and VAN HOVE, G. (2011) 'Swimming Is Never Without Risk: Opening Up on Learning through Activism and Research'. Qualitative Inquiry 17(2): 224-232.

DÜVELL, F., TRIANDAFYLLIDOU, A. and VOLLMER, B. (2010) 'Ethical Issues in Irregular Migration Research in Europe'. Population Space and Place 16(3): 227-239.

DUYNDAM, J. and POORTHUIS, M. (2003) Levinas. Rotterdam: Lemniscaat.

EGÉA-KUEHNE, D. (2008) 'Levinas's Quest for Justice: Of Faith and the "Possibility of Educations"'. In Egéa-Kuehne, D. (ed.) Levinas and Education: At the Intersection of Faith and Reason. New York, NY: Routledge, pp. 26-40.

ELLIS, C. (2007) 'Telling Secrets, Revealing Lives: Relational Ethics in Research with Intimate Others'. Qualitative Inquiry 13(1): 3-29.

ETHICAL RESEARCH INVOLVING CHILDREN (ERIC) (2014) International Charter for Ethical Research Involving Children, http://childethics.com/charter/ (accessed 26 October 2014).

EUROPEAN MIGRATION NETWORK (EMN) (2010) Policies on Reception, Return and Integration Arrangements for, and Numbers of, Unaccompanied Minors: An EU Comparative Study. Brussels: European Migration Network.

EUROPEAN UNION AGENCY FOR FUNDAMENTAL RIGHTS (FRA) (2010) Separated, Asylum Seeking Children in European Union Member States: Comparative Report. Vienna: European Union Agency for Fundamental Rights.

FAZEL, M., REED, R.V., PANTER-BRICK, C. and STEIN, A. (2012) 'Mental Health of Displaced and Refugee Children Resettled in High-Income Countries: Risk and Protective Factors'. Lancet 379(9812): 266-282.

GUILLEMIN, M. and GILLAM, L. (2004) 'Ethics, Reflexivity, and "Ethically Important Moments" in Research'. Qualitative Inquiry 10(2): 261-280.

GUZDER, J. and ROUSSEAU, C. (2013) 'A Diversity of Voices: McGill "Working with Culture" Seminars'. Culture, Medicine and Psychiatry Journal 37(2): 347-364.

HOFFMAN, M.L. (2000) Empathy and Moral Development: Implications for Caring and Justice. Cambridge, UK: The Press Syndicate of the University of Cambridge.

HOPKINS, P. (2008) 'Ethical Issues in Research with Unaccompanied Asylum-Seeking Children'. Childrens Geographies 6(1): 37-48.

hUgman, R., BARTOlOMaI, L. and PITTAWAy, E. (2011a) 'Human Agency and the Meaning of Informed Consent: Reflections on Research with Refugees'. Journal of Refugee Studies 24(4): 655-671.

HUGMAN, R., PITTAWAY, E. and BARTOlOMEI, L. (2011b) 'When "Do No Harm" Is Not Enough: The Ethics of Research with Refugees and Other Vulnerable Groups'. British Journal of Social Work 41(7): 1271-1287.

HYNES, T. (2003) 'The Issue of "Trust" or "Mistrust" in Research with Refugees: Choices, Caveats and Considerations for Researchers', The UN Refugee Agency [UNHCR], Evaluation and Policy Analysis Unit, New Issues in Refugee Research. London: Middlesex University. 


\section{Marianne Vervliet et al.}

JACOBSEN, K. and LANDAU, L.B. (2003) 'The Dual Imperative in Refugee Research: Some Methodological and Ethical Considerations in Social Science Research on Forced Migration'. Disasters 27(3): 185-206.

KOHLI, R.K.S. (2006) 'The Comfort of Strangers: Social Work Practice with Unaccompanied Asylum-Seeking Children and Young People in the UK'. Child \& Family Social Work 11(1): $1-10$.

KUCZINSKI, L. (2003) 'Beyond Bidirectionality: Bilateral Conceptual Frameworks for Understanding Dynamics in Parent-Child Relations'. In Kuczynsky, L. (ed.) Handbook of Dynamics in Parent-Child Relations. London: SAGE, pp. 1-23.

LEANING, J. (2001) 'Ethics of Research in Refugee Populations'. Lancet 357(9266): 1432-1433.

LUSTER, T., QIN, D., BATES, L., RANA, M. and LEE, J.A. (2010) 'Successful Adaptation among Sudanese Unaccompanied Minors: Perspectives of Youth and Foster Parents'. Childhood 17(2): 197-211.

MACKENZIE, C., MCDOWELL, C. and PITTAWAY, E. (2007) 'Beyond "Do No Harm": The Challenge of Constructing Ethical Relationships in Refugee Research'. Journal of Refugee Studies 20(2): 299-319.

MORSE, J.M. (2007) 'Ethics in Action: Ethical Principles for Doing Qualitative Health Research'. Qualitative Health Research 17(8): 1003-1005.

NEWMAN, E. and KALOUPEK, D.G. (2004) 'The Risks and Benefits of Participating in Trauma-Focused Research Studies'. Journal of Traumatic Stress 17(5): 383-394.

NI RAGHALLAIGH, M. and GILLIGAN, R. (2010) 'Active Survival in the Lives of Unaccompanied Minors: Coping Strategies, Resilience, and the Relevance of Religion'. Child \& Family Social Work 15(2): 226-237.

ROUSSEAU, C. and KIRMAYER, L.J. (2010) 'From Complicity to Advocacy: The Necessity of Refugee Research'. American Journal of Bioethics 10(2): 65-67.

ROUSSEAU, C., MAESHAM, T. and MORO, M.R. (2011) 'Working with Interpreters in Child Mental Health'. Child and Adolescent Mental Health 16(1): 55-59.

THOMAS, S. and BYFORD, S. (2003) 'Research with Unaccompanied Children Seeking Asylum'. British Medical Journal 327(7428): 1400-1402.

UNITED NATIONS HIGH COMMISSIONER FOR REFUGEES (UNHCR) (2013) UNHCR Global Trends 2012, http://www.unhcr.org/51bacb0f9.html (accessed 26 October 2014).

UNITED NATIONS HIGH COMMISSIONER FOR REFUGEES (UNHCR) (2014) UNHCR Global Trends 2013, http://www.unhcr.org/5399a14f9.html (accessed 26 October 2014).

VERVLIET, M., DE MOL, J., BROEKAERT, E. and DERLUYN, I. (2013a) 'That I Live, That's Because of Her.' Intersectionality as a Framework for Unaccompanied Refugee Mothers'. British Journal of Social Work, Available at http://bjsw.oxfordjournals.org/content/ early/2013/03/27/bjsw.bct060.abstract (accessed 22 July 2013).

VERVLIET, M., LAMMERTYN， J., BROEKAERT, E. and DERLUYN， I. (2013b) 'Longitudinal follow-up of the mental health of unaccompanied refugee minors'. European Child \& Adolescent Psychiatry 23: 337-346.

VERVLIET, M., MEYER DEMOTT, M., JAKOBSEN, M., TROND, H., BROEKAERT, E. and DERLUYN, I. (2013c) 'The mental health of unaccompanied refugee minors on arrival in the host country'. Scandinavian Journal of Psychology 55: 33-37.

VANDEKINDEREN, C., ROETS, G. and VAN HOVE, G. (2013) 'The Researcher and the Beast: Uncovering Processes of Othering and Becoming Animal in Research Ventures in the Field of Critical Disability Studies'. Qualitative Inquiry, http://qix.sagepub.com/content/early/ 2013/06/13/1077800413489267.abstract (accessed 26 October 2014).

ZION, D., BRISKMAN, L. and LOFF, B. (2010) 'Returning to History: The Ethics of Researching Asylum Seeker Health in Australia'. American Journal of Bioethics 10(2): 48-56.

ZWI, K.J., HERZBERG, B., DOSSETOR, D. and FIELD, J. (2003) 'A Child in Detention: Dilemmas Faced by Health Professionals'. Medical Journal of Australia 179(6): 319-322. 